\title{
Development, Physical-Chemical Stability, and Release Studies of Four Alcohol-Free Spironolactone Suspensions for Use in Pediatrics
}

e-mail: nora.provenza@hotmail.com nprovebe7@alumnes.ub.edu

\author{
Nora Provenza Bernal'*, Ana C. Calpena ${ }^{1}$, Mireia Mallandrich', \\ Adolfina Ruiz ${ }^{2}$, and Beatriz Clares ${ }^{2}$ \\ ${ }^{1}$ Department of Pharmacy and Pharmaceutical Technology, Faculty of Pharmacy, University of Barcelona. Avda. Joan XXIII s/n, 08028 \\ Barcelona, Spain \\ ${ }^{2}$ Department of Pharmacy and Pharmaceutical Technology, Faculty of Pharmacy, University of Granada. Campus of Cartuja street $s / n$, \\ 18071 Granada, Spain
}

\begin{abstract}
Dissolution studies have become of great significance because, in most cases, drug dissolution is the rate-limiting step in the absorption process. As occurs with solid oral dosage forms, heterogeneous dispersed systems (suspensions) could also have some problems with their in vitro dissolution.

The objective of this study was to evaluate the influence of excipients on the release of spironolactone from four alcohol-free suspensions (pharmaceutical compounding) of spironolactone $5 \mathrm{mg} / \mathrm{mL}$ suitable for pediatric use.

In addition, the comparison of the physical and chemical stability of the suspensions stored at 4,25 , and $40^{\circ} \mathrm{C}$ over a 60-day period has been studied. Rheological behavior, particle size, a prediction of long-term physical stability, $\mathrm{pH}$, and assay of spironolactone by HPLC were assessed at preset times. The dissolution profile of each suspension was determined and compared with that of the commercial tablets. A microbiological study of the best formula was also performed. Chemically, the four spironolactone suspensions were stable for 60 days stored at three temperatures; Suspension IV had optimum $\mathrm{pH}$ values and the highest recovery percentage. In terms of physical stability, sedimentation occurred in Suspension IV, and flotation of spironolactone occurred in Suspensions I, II, and III. Suspension III had the highest viscosity and the slowest drug release. Suspension IV was also microbiologically stable for 60 days. In conclusion, Suspension IV had the best properties. The least suitable form was Suspension III, as its high viscosity made it difficult to achieve homogeneous redispersion and it had the slowest dissolution profile.
\end{abstract}

KEYWORDS: Spironolactone, oral suspension, pediatrics, dissolution.

\section{INTRODUCTION}

S pironolactone is a competitive aldosterone antagonist that acts at the distal convoluted renal tubule to increase sodium and water excretion and reduce potassium elimination (1). The use of spironolactone in infants and children was first reported in 1964 (2) when administration of the drug to three infants produced moderate dieresis. Since then, spironolactone has been widely utilized in the management of congestive heart failure associated with congenital heart disease (3-5), bronchopulmonary dysplasia or chronic lung disease (5-7), and pediatric ascites $(8,9)$.

In many countries, spironolactone is marketed only as tablets. This is an ongoing problem for some groups of the population such as children, patients who cannot swallow solid dosage forms, patients who must receive medications via nasogastric or gastronomy tubes, and patients who require nonstandard doses that are more easily and accurately measured using a liquid formulation (10).

\footnotetext{
${ }^{*}$ Corresponding author.
}

From birth to adulthood, a series of anatomical, physiological, and biochemical modifications are produced that affect the absorption, distribution, metabolism, and excretion of drugs and their mechanisms of action, as well as enzyme synthesis and the production and distribution of receptors $(11,12)$. Thus, drug prescribing must be based on knowledge of pharmacokinetic and pharmacodynamic characteristics (13).

Studies of novel dosage forms, such as mini-tablets, that are more appropriate for children (14) are now being carried out. However, orally administered liquids are still considered one of the standard forms for this population. Extemporaneous oral liquid medicines are easily prepared and allow dosage flexibility $(1,15)$. A single liquid pediatric preparation may be used for infants and children of all ages, with the dose of the drug varied by the volume administered (16). It is common practice for liquid dosage forms to be prepared from a commercially available oral solid dosage by simply crushing tablets or opening a capsule (10). However, the use of an active pharmaceutical ingredient (API) obtained by modifying a commercially available tablet or capsule could have clinical and legal implications (17). 
Therefore, due to the lack of products tailored to the needs of this population, especially newborns, pharmaceutical compounds (solutions or suspensions) need to be prepared as an alternative to marketed tablets. However, there is limited information on the suitability and stability of liquid preparations (18). The variability in the design of such preparations, sometimes with unknown low stability, leads to the possibility of medication errors in the handling of the dosages. Furthermore, dosage or stability control is not carried out in pharmacies or hospitals, as the indicators are determined by methods such as high performance liquid chromatography $(\mathrm{HPLC})$ that require considerable effort (19).

Over the last 30 years, many extemporaneously prepared spironolactone-containing oral liquid formulations have been reported in the literature $(1,20-26)$, and data on their physical and chemical stability have been gathered. However, some of them were prepared using crushed tablets; others contain alcohol, which is not desirable for children, to improve stability or drug solubility. Due to genetic polymorphism, metabolism of alcohol could differ among races. As these preparations are addressed to a pediatric population, it is desirable to avoid the presence of alcohol in these formulations. Other studies were carried out at a different temperature. Therefore, the purpose of the present study was to investigate four alcohol-free suspensions of spironolactone (pure powder) that are suitable for a pediatric population and compare their physical and chemical stability at three different temperatures, to ensure the quality and the right preparation and storage of these preparations. Additionally, to assess the influence of the excipients on the release of the active substance, the dissolution profile of each suspension was analyzed and compared with that of the marketed tablets. A microbiological study of the best formulation was also carried out.

\section{MATERIAL AND METHODS \\ Materials}

Spironolactone, simple syrup, glycerin, carboxymethylcellulose, Excipient Acofar for Syrup (sucrose, water, sorbitol, glycerin, flavoring, citric acid, methylparaben, potassium sorbate, sodium phosphate, and coloring), and Excipient Acofar for Suspensions (water, sodium carboxy- methylcellulose, cellulose gum, citric acid, calcium sulfate, sodium phosphate, methylparaben, carrageenan, xanthan gum, potassium sorbate, sucrose, sorbitan triestearate, PEG-40 stearate, dimethicone, and silica) were purchased from Acofarma, S.A. (Barcelona, Spain). The tablets containing $25 \mathrm{mg}$ of spironolactone (commercially available in Spain) that were used for the dissolution test were purchased from a community pharmacy. Methanol was purchased from Panreac (Barcelona, Spain), and doubledistilled water was used after filtration in a Milli-Q Gradient A10 system apparatus (Millipore Ibérica S.A.U., Madrid, Spain). All chemicals were of analytical grade.

\section{Preparation of Spironolactone Suspensions}

The composition of the four suspensions of spironolactone is shown in Table 1.

To make Suspension I (Spl), simple syrup was placed in a glass container and spironolactone was added to the simple syrup under mechanical stirring (UltraTurrax, lka, Germany) until a homogeneous suspension was achieved. To prepare Suspension II (Spll), spironolactone was mixed with glycerin until a homogeneous white paste was formed. Then, simple syrup was added slowly under stirring. To prepare Suspension III (SpIII), spironolactone was mixed with glycerin until a homogeneous white paste was formed. Then, $20 \mathrm{~g}$ of a carboxymethylcellulose gel prepared the day before at a concentration of $1 \%$ was added. Once everything was well mixed, simple syrup was added slowly under magnetic stirring. For the preparation of Suspension IV (SpIV), spironolactone was mixed with glycerin until a homogeneous white paste was formed. Then, Excipient Acofar for Suspension was added under stirring, and finally the mixture was brought to volume with Excipient Acofar for Syrups. As a control, the same amounts of each formulation (Spl, Spll, Splll, and SpIV) without spironolactone (blank samples) were prepared similarly. All the formulations, with and without spironolactone, were stored under the same conditions for further analysis.

\section{Stability Test and Suspension Characterization}

After the preparation, aliquots of $10 \mathrm{~mL}$ of the suspensions were stored in amber glass vials at three temperatures $\left(4,25\right.$, and $\left.40^{\circ} \mathrm{C}\right)$ for 2 months. Measures were performed at selected times at $0,7,15,30$, and 60 days.

Table 1. Spironolactone Suspension Composition

\begin{tabular}{|c|c|c|c|c|}
\hline Component & Spl & Spll & SpIII & SplV \\
\hline Spironolactone (mg) & 500 & 500 & 500 & 500 \\
\hline Glycerin (\% m/v) & - & 10 & 10 & 5 \\
\hline Carboximetylcelulose (\% m/v) & - & - & 0.2 & - \\
\hline Symple syrup (mL) & q.s. 100 & q.s. 100 & q.s. 100 & - \\
\hline Excipient Acofar for Suspensions (mL) & - & - & - & 50 \\
\hline Excipient Acofar for Syrups (mL) & - & - & - & q.s. 100 \\
\hline
\end{tabular}


Analyses involved the physical and chemical testing of quantifiable parameters that could possibly change during storage, such as appearance, rheological behavior, particle size, optical stability by multiple light scattering, $\mathrm{pH}$, and active substance quantity. Microbiological stability was also assessed.

Preparations were considered stable if the physical characteristics did not change and the drug concentration remained greater than $90 \%$ of the original concentration (1).

\section{Physical Stability}

Appearance

The samples stored at each temperature were visually examined to assess parameters such as odor, color, and tendency to precipitate or float.

\section{Rheological Behavior}

The rheological behavior of the formulations was assessed at $25^{\circ} \mathrm{C}$ using a rotational HAAKE Rheostress 1 rheometer (Thermo Fisher Scientific, Karlsruhe, Germany) equipped with a parallel plate geometry setup, with a fixed lower plate and an upper plate (Haake PP60 Ti, $6 \mathrm{~cm}$ diameter). Different gaps between plates were tested, and a separation of $0.5 \mathrm{~mm}$ was selected. Viscosity curves and flow curves $(n=3)$ were recorded for 3 min during the ramp-up period from 0 to $100 \mathrm{~s}^{-1}, 1 \mathrm{~min}$ at $100 \mathrm{~s}^{-1}$ (the constant shear rate period), and 3 min during the rampdown period from 100 to $0 \mathrm{~s}^{-1}$. The viscosity values at 100 $\mathrm{s}^{-1}$ were determined at $t_{0}$ and $t=60$ days for the samples stored at 4,25 , and $40^{\circ} \mathrm{C}$.

Data from the flow curve (when it showed that the fluid was non-Newtonian) were fitted to various mathematical models: Ostwald-de Waele, Carreau-Yasuda, Cross, and Herschel-Bulkley.

$$
\begin{array}{llrl}
\text { Ostwald-de Waele } & \tau & =\mathrm{k} \times(\gamma)^{\mathrm{n}} \\
\text { Carreau-Yasuda } & \tau & =\frac{\dot{\gamma}\left(\eta_{0}-\eta_{\infty}\right)}{\left(1+(\lambda \dot{\gamma})^{a}\right)^{(1-n) / a}} \\
\text { Cross } & \tau=\frac{\dot{\gamma}\left(\eta_{\infty}+\left(\eta_{0}-\eta_{\infty}\right)\right.}{1+\left(\dot{\gamma} / \dot{\gamma}_{0}\right)^{n}} \\
\text { Herschel-Bulkley } & \tau=\tau_{0}+k_{1} \times(\gamma)^{\mathrm{n}}
\end{array}
$$

where $\tau$ is the shear stress, $\gamma$ is the shear rate $(1 / \mathrm{s}), \tau_{0}$ is the yield shear stress $(\mathrm{Pa}), \gamma_{0}$ is the zero shear rate $(1 / \mathrm{s}), \eta$ is the infinite shear rate viscosity, $\eta_{0}$ is the zero shear rate viscosity (Pa.s), $k$ is the consistency coefficient(s), and $n$ is a dimensionless rate constant. The fluid is Newtonian if $n=1$, pseudoplastic if $0<n<1$, and dilatant if $n>1$.

\section{Particle Size}

The particle size distribution (PSD) of the spironolactone suspensions was carried out by laser diffraction (LD, 2000E
Mastersizer, Malvern, UK). The average particle size distribution was measured from six replicates of each sample. Suspensions were diluted with purified water. Data were evaluated using the volume distribution method, and characterization parameters were D10, D50, and D90 (i.e., D90 of $1 \mu \mathrm{m}$ means that $90 \%$ of volume of particles have a diameter of $1 \mu \mathrm{m}$ or less). To evaluate the changes in the PSD of the suspensions, samples stored at room temperature $\left(25^{\circ} \mathrm{C}\right)$ were measured at days 0 and 60 .

Prediction of Long-Term Physical Stability of the Suspensions Technology based on the analysis of multiple light scattering was used to predict the long-term physical stability of suspensions. Turbiscan Lab (Formulaction Co., L'Union, France) is an optical instrument that characterizes concentrated emulsions and dispersions. The analyzed suspension is placed on a cylindrical glass measuring cell. The light source is pulsed near infrared $(\lambda=880 \mathrm{~nm})$. Two synchronous optical sensors receive light transmitted through the sample $\left(0^{\circ}\right.$ from the incident radiation, transmission [T] sensor) and light backscattered by the sample $\left(135^{\circ}\right.$ from the incident radiation, backscattering $[\mathrm{BS}]$ detector). The principle of this measurement is based on variation in the particle volume fraction (migration) or mean size (coalescence), which results in variations in the BS and T signals (27-29). Therefore, this technique was used to detect changes in the location of particles in the suspensions. Measurements were performed at $25^{\circ} \mathrm{C}$.

\section{Chemical Stability}

\section{$\mathrm{pH}$ Measurements}

The $\mathrm{pH}$ values $(n=3)$ were measured by immersing the probe directly into the sample using a digital $\mathrm{pH} / \mathrm{mV}$ meter (Micro-pH 200, Crison Instruments S.A., Barcelona, Spain). The $\mathrm{pH}$ was measured at three temperatures at selected times ( $0,7,15,30$, and 60 days). A significant variance in $\mathrm{pH}$ over an adequate value per formula could indicate degradation of the pharmaceutical compounding or erroneous preparation.

\section{Suspension Uniformity and Spironolactone Stability}

Homogeneity of the suspensions was examined at $t=0$ to ensure that every vial contained not less than $90 \%$ and no more than $110 \%$ of the theoretically calculated and labeled amount of spironolactone per unit volume. Six samples were taken from each vial, and spironolactone content was assayed using the high performance liquid chromatography (HPLC) method described below. Relative standard deviation (\%RSD) was used to assess the homogeneity of the suspensions.

To evaluate the stability of spironolactone in the suspensions stored at the three temperatures, an analysis $(n=6)$ was carried out during the storage period (at 0,7 , 15,30 , and 60 days) using the HPLC quantification technique described below. Preparations were considered 
stable if the active substance was within $\pm 10 \%$ of the original amount.

To carry out the analysis, $250 \mu \mathrm{L}$ of suspension equivalent to $1.25 \mathrm{mg}$ of spironolactone was diluted with 100 $\mathrm{mL}$ of methanol/water (30:70) in an amber glass flask to obtain a final spironolactone concentration of $12.5 \mu \mathrm{g} / \mathrm{mL}$. The solution was sonicated for $1 \mathrm{~min}$ in an ultrasonic bath (P-selecta 514, Vidrafoc, Barcelona, Spain) and then spotted and analyzed for spironolactone content.

\section{Apparatus and Conditions}

The HPLC system consisted of a Waters 717 Plus autosampler (Waters, Milford, MA, USA) equipped with an Atlantis dC18 column $(4.6 \times 150 \mathrm{~mm}, 5-\mu \mathrm{m})$ and a UV-vis detector (Waters, Milford, MA, USA) set at $242 \mathrm{~nm}$. The mobile phase was methanol/water (37:63) delivered at a flow rate of $0.8 \mathrm{~mL} / \mathrm{min}$. It was filtered through a $0.45-\mu \mathrm{m}$ membrane and degassed by sonication prior to use. The injection volume was $50 \mu \mathrm{L}$.

To assess the presence of canrenone, the main degradation product of spironolactone (30), a preliminary comparative study at 242 and $280 \mathrm{~nm}$ was carried out on a sample stored at $70{ }^{\circ} \mathrm{C}$ for 15 days under the conditions mentioned above.

\section{Analytical Validation Calibration Standards}

Calibration curves containing six standards from 25 to $0.78 \mu \mathrm{g} / \mathrm{mL}(25,12.5,6.25,3.13,1.56$, and $0.78 \mu \mathrm{g} / \mathrm{mL})$ were prepared by making dilutions with appropriate volumes of methanol/water (30:70).

The methodology was validated according to International Conference on Harmonization guidelines Q2 (R1) $(31,32)$ and included an evaluation of the following characteristics: linearity, sensitivity, precision, accuracy, and limits of detection and quantification.

Calibration curves were validated interday $(n=6)$. A linear regression analysis was performed. Furthermore, linearity was determined by a one-way analysis of variance (ANOVA) test of response factors (ratio of peak areas versus nominal concentrations of each standard), and differences were considered statistically significant when $p<0.05$.

The selectivity of the assays was checked by individual analysis of blank samples stored at the corresponding temperatures.

The determination of the limits of detection (LOD) and quantification (LOQ) was based on the standard deviation of the response (SD) and the slope of the calibration curve $(S)$ according to the following equations:

$$
\mathrm{LOD}=3.3(S D / S) \text { and } \mathrm{LOQ}=10(S D / S)
$$

Accuracy was evaluated by means of the relative error (\%), and intermediate precision was expressed as the relative standard deviation (RSD) of replicates in percentage. The maximum acceptable levels were $10 \%$ in both cases.

\section{Dissolution Test (In Vitro Drug Release Studies)}

The test was performed according to USP <711> (33) using a paddle apparatus (Apparatus 2) SR8 PLUS (Hanson Research, Canada) at $37^{\circ} \mathrm{C}$ and $75 \mathrm{rpm}$. Tablets or the suspensions (equivalent to $25 \mathrm{mg}$ of spironolactone) were held in different vessels $(1000 \mathrm{~mL})$. The suspension sample $(5 \mathrm{~mL}$ ) was taken using a syringe and quantitatively transferred to the vessel at the top of the dissolution medium. To calculate the exact weight of suspension added to the vessel, the syringe was weighed at three stages: empty, filled with the suspension, and after the sample was expelled into the dissolution vessel. Aliquots were removed from the vessel and replaced with fresh dissolution medium $(0.1 \mathrm{~N} \mathrm{HCl}$ containing $0.1 \%$ sodium lauryl sulfate) at predetermined time intervals. For rapidly dissolving products including suspensions, useful information may be obtained from earlier points (33), thus aliquots were removed at 2, 5, 8, 12, 15, 20, 25, 30, 40, 50, and $60 \mathrm{~min}$ for the tablets and at 1, 2, 3, 4, 5, 6, 7, 8, 9, 10, $11,12,13,14,15$, and 60 min for the suspensions. Spironolactone content was analyzed by spectrofluorometry at $242 \mathrm{~nm}$ using an Amersham Biosciences Ultrospec 1100 Pro UV-vis spectrophotometer (Amersham Biosciences, Piscataway, NJ, USA) at room temperature.

The method for quantifying spironolactone was also validated following the procedure described above. In this case, the solvent for the preparation of standard solutions was the dissolution medium.

Three kinetic models (a one-phase exponential association, a two-phase association model, and Boltzmann sigmoid) were used to fit the experimental data from the drug release experiment:

One-phase exponential

$$
y=y_{\max }\left(1-e^{-k x}\right)
$$

association

Two-phase association model

Boltzmann sigmoid

$$
y=y_{\max 1}\left(1-e^{-k_{1} x}\right)+y_{\max 2}\left(1-e^{-k_{2} x}\right)
$$

\section{A nonlinear regression was performed using Prism} software, V. 3.00 (GraphPad Software Inc., San Diego, CA, USA). In addition, Akaike's information criterion (AIC) was determined for each model, as it is an indicator of model suitability for a given data set (34). The smaller the value of $A / C$, the better the model fits the data.

In addition, some non-model parameters such as dissolution efficiency $(D E)$ and mean dissolution time (MDT) were calculated from the in vitro release data. These parameters are very useful for comparing profiles types, 
as an evaluation of the dissolution characteristics of the formulations is not conditioned by the goodness of the fit to a theoretical model of our data (35). The $D E(\%)$ was calculated by means of the following equation:

$$
D E(\%)=\frac{\dot{\gamma} \int_{0}^{t} M \times d t}{C_{100} \times t} \times 100
$$

where the numerator represents the area under the dissolution curve up to a certain time $t$, and the denominator is the rectangular area between the total amount of drug released and the last experimental time point $t$. For the area under the dissolution curve (AUC) calculation, a continuous plot of the evolution of released quantities across the whole of the experimental time was calculated. Afterwards, respective AUC values were calculated by means of a trapezoidal rule for the whole time values interval.

$M D T$ is defined as the mean residence time of a drug in the formulation. It is a useful parameter for characterizing drug release rate from a dosage form. It was calculated using the equation:

$$
M D T=\frac{\sum_{i=1}^{n} \overline{t_{i}} \times \Delta M_{i}}{M_{\infty}}
$$

where $i$ is the sample number, $n$ is the number of dissolution sample times, $\bar{t}_{i}$ is the time at the midpoint between $t_{i}$ and $t_{i-1}$ calculated with the expression $\left(t_{i}+t_{i-1}\right) / 2, \Delta M_{i}$ is the increase in the amount of drug released at each time interval, and $M_{\infty}$ is the asymptote of the dissolved amount of drug.

\section{Microbiological Stability}

A microbiological test of the suspension that had the best characteristics was performed according to the European Pharmacopoeia monograph, Microbiological examination of non-sterile products (30). The microbial count is the average number of colony forming units (cfu) found in agar. Oral solutions meet microbial requirements if the total aerobic microbial count is below $10^{2} \mathrm{cfu} / \mathrm{mL}$, the total combined yeast/mold count is below $10^{1} \mathrm{cfu} / \mathrm{mL}$, and the absence of Escherichia coli is confirmed.

\section{Statistical Analysis}

Data were statistically analyzed by the Student's $t$-test or one-way ANOVA for comparisons of three or more groups of data. The level of significance was set at $p<0.05$ using Prism V.3 software (GraphPad Software, Inc., San Diego, CA).

\section{RESULTS AND DISCUSSION}

The preparation of extemporaneous formulations often involves the use of commercial dosage forms and their conversion into something patients can easily swallow
(36). However, the use of an API from the modification of a commercially available tablet or capsule could have legal and clinical implications (17). Therefore, pure powder was used to prepare the solutions. Glycerin was used to decrease the interfacial tension between the drug as a solid and the rest of the liquid, as spironolactone is practically insoluble in water. In Splll, a suspending agent (carboxymethylcelullose) was chosen to increase viscosity and keep the suspended solid homogeneously distributed inside the formulation for longer. A concentration of $0.2 \%$ (w/v) was enough for this purpose. Excipient Acofar for Syrups and Excipient Acofar for Suspensions, used in SpIV, are commercially available in some European countries and are useful to pharmacists in the preparation of formulations.

\section{Physical Stability}

All the formulations were redispersible suspensions. Spl, Spll, and SpIII were white, whereas SpIV was slightly pink with a characteristic fruity odor at $t_{0}$. There were no detectable changes in color and odor in any sample during the two months of storage at the three controlled temperatures.

Oral viscosity plays an important role in the perception of the texture of liquid or fluid pharmaceuticals. Several instrumental measurements have been described to correlate closely with perceived viscosity and therefore describe the thickness signal interpreted by the brain. For example, oral shear stress is calculated from the assumption that the mouth is comparable to parallel plate geometry on a rheometer (37). Viscosity measurements were made with an imposed shear rate $(\gamma)$, and the resulting shear stress $(\tau)$ was measured. This type of test can be used to determine if the material is characterized by linear-viscous (Newtonian) behavior (shear-stress exponent $n=1$ ) in the investigated shear rate range or if it shows power-law behavior $(n \neq 1)$. The potential dependence of the viscosity of the solutions on the shear rate is shown in Figure 1.

The curves for Spl and Spll show constant viscosity values with an increasing shear rate from 0 to $100 \mathrm{~s}^{-1}$, and thus the behavior was Newtonian. In both cases, the slope of the flow curve is constant, and the graph of viscosity is a line $(38,39)$. The curves for SpIII and SpIV are slightly dependent on shear rate, showing a consistent, although relatively small, decrease in viscosity with increasing shear rate from 0 to $100 \mathrm{~s}^{-1}$. This is the typical behavior of pseudoplastic fluids. In all cases, the hysteresis loop is inappreciable, which indicates that SpIII and SpIV did not show thixotropy.

Viscosity values at $100 \mathrm{~s}^{-1}$ were $0.110,0.130,0.450$, and $0.030 \mathrm{~Pa} \cdot \mathrm{s}$ for Spl, Spll, Splll and SpIV, respectively, at $t_{0}$. As shown in Table 2, no statistically significant differences were observed at $t_{60}$ for the samples of all the suspensions stored at 4 and $25^{\circ} \mathrm{C}$. A small decrease in the viscosity of SpllI and SpIV was observed $(p<0.05)$ at $t_{60}$ in the samples 


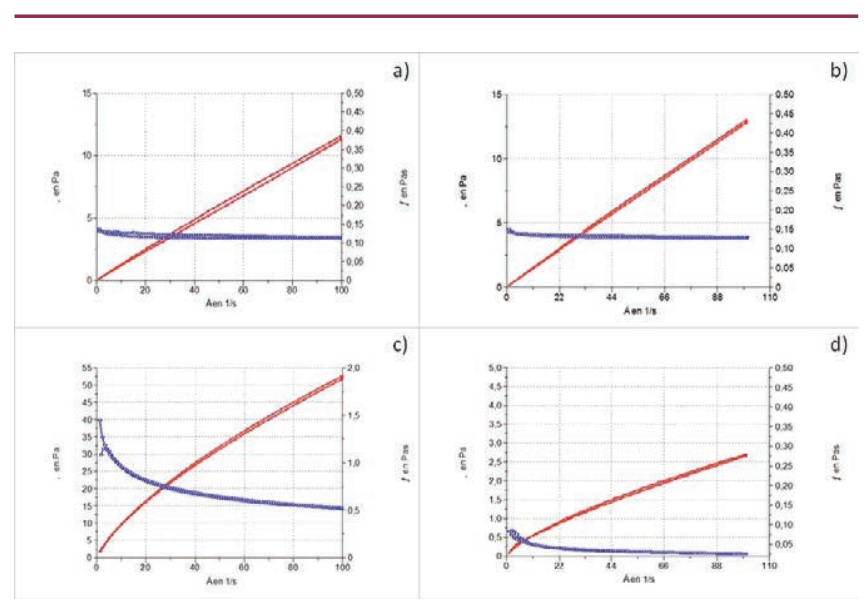

Figure 1. Rheograms of Suspensions (a) I, (b) II, (c) III, and (d) IV. The red line is shear stress $(\mathrm{Pa})$, and the blue line is viscosity $(\mathrm{Pa} \cdot \mathrm{s})$.

stored at $40^{\circ} \mathrm{C}$. This is the normal behavior of CMC solutions (40). Rheological stability is an important requirement, because the dosage process should ensure uniform distribution of the active substance within the suspension, especially among pediatric patients.

The suspensions that contained simple syrup had higher viscosity values than SpIV due to the higher concentration of sucrose. Splll had the highest viscosity value, probably due to the mixture of carboxymethylcelulose and simple syrup (40). Glycerin did not influence viscosity, as Spl and Spll had similar viscosity values.

For SpIII and SpIV (pseudoplastic), Ostwald-de Waele, Carreau-Yasuda, Cross, and Herschel-Bulkley mathematical models were fitted to the data of the flow curve to identify the model that provided the best overall match of the experimentally observed rheological data. The criterion for selecting the most appropriate model was based on finding the best fit, with the highest correlation coefficient of the linear regressions $(r)$ and the lowest chi square value. Such a model provided the best statistical description of the rheological behavior. The model that best fit the experimental data in all cases was Cross, probably due to the presence of CMC (41). The accompanying results of the Cross model constants are listed in Table 3. In both cases, the rate index $n$ remains constant at the end of the study regardless of the temperature.
Physical characteristics, particularly the particle size of the drug substance, are very important for suspensions (42). The PSD in the finished drug product dosage form is a critical parameter that significantly affects the bioavailability and pharmacokinetics of the product (43). Particle size was determined by LD at day 0 (just after the preparation of the suspensions) and at the end of the study $\left(t_{60}\right)$.

All of the suspensions were coarse dispersions (as classified by Ostwald), since the particle size was greater than $1 \mu \mathrm{m}$. Particles in suspension have a surface free energy that makes the system unstable. The free energy of the system depends on the total surface area and the interfacial tension between the liquid medium and the solid particles. Thus, to minimize the free energy, the system tends to decrease the surface area, which is achieved by the formation of agglomerates (43). This was the case for Spl, which was the suspension with the largest particle size. Spll, Splll, and SpIV had smaller particle sizes, as the presence of a wetting agent helps to lower the liquid-air interfacial tension. This enables the solvent to penetrate into the loose agglomerates of powder and thus displace the air from the pores of the individual particles (43). The results (Table 4) show that the distribution was consistent for Spl over the 60-day period, as both D10\% and D90\% were stable after 60 days. A very slight increase in PSD by day 60 in comparison with the values obtained at $t_{0}$ was observed for Spll, Splll, and SpIV.

Turbiscan Lab, an optical analyzer, was also used to detect destabilization phenomena. In comparison with classical stability measurements, this technique assesses physical stability without diluting or modifying the formulation (29). To assess the optical stability, Turbiscan Lab scans at various preprogrammed times and overlays the profiles on one graph to show the destabilization. Migration phenomena are displayed by local variations of backscattering (Figure 2). Backscattering fluxes are shown on the ordinate, and the height of the cell on the abscissa. The first profile is displayed in pink, and the last one in red. As expected, all of the suspensions were unstable systems. In SpIV, the backscattering level dropped at the top (right side of the spectrum) due to a decrease in the concentration of particles. Hence, the suspension clarified in this area. At the bottom of the suspension, there was an increase in particle concentration because of sediment

Table 2. Suspension Viscosity (Pa.s) at $t_{60}$ at 4,25 , and $40^{\circ} \mathrm{C}$

\begin{tabular}{cccc}
\hline Suspension & & \multicolumn{2}{c}{ Temperature } \\
\cline { 2 - 3 } & $\mathbf{4}^{\circ} \mathbf{C}$ & $\mathbf{2 5}^{\circ} \mathbf{C}$ & $\mathbf{4 0}{ }^{\circ} \mathbf{C}$ \\
\hline Spl & $0.108 \pm 3.4 \times 10^{-3}$ & $0.107 \pm 3.1 \times 10^{-3}$ & $0.106 \pm 4.3 \times 10^{-3}$ \\
\hline Spll & $0.123 \pm 2.9 \times 10^{-3}$ & $0.120 \pm 4.7 \times 10^{-3}$ & $0.106 \pm 4.3 \times 10^{-3}$ \\
\hline Splll & $0.453 \pm 3.0 \times 10^{-3}$ & $0.445 \pm 3.6 \times 10^{-3}$ & $0.408 \pm 1.1 \times 10^{-3}\left({ }^{*}\right)$ \\
\hline SplV & $0.453 \pm 3.0 \times 10^{-3}$ & $0.031 \pm 9.4 \times 10^{-4}$ & $0.022 \pm 7.9 \times 10^{-4}(*)$ \\
\hline
\end{tabular}

\footnotetext{
* Statistical significant differences $(p<0.05)$ regarding $t=0$.
} 
Table 3. Fitted Parameters for Effect of Temperature and Time on Flow Behavior of SpIII and SpIV

\begin{tabular}{|c|c|c|c|c|c|c|c|}
\hline \multirow[b]{2}{*}{ Time/Temperature } & \multirow[b]{2}{*}{ Formulation } & \multicolumn{6}{|c|}{ Parameter } \\
\hline & & $\eta_{0}$ & $\boldsymbol{\eta}_{\infty}$ & $\gamma_{0}$ & $n$ & $\mathrm{Chi}^{2}$ & $r$ \\
\hline \multirow[t]{2}{*}{$t_{0}\left(25^{\circ} \mathrm{C}\right)$} & Suspension III & 1.706 & 0.226 & 12.090 & 0.625 & 0.442 & 1 \\
\hline & Suspension IV & 0.186 & 0.014 & 1.217 & 0.516 & 0.003 & 1 \\
\hline \multirow[t]{2}{*}{$t_{60}\left(4^{\circ} \mathrm{C}\right)$} & Suspension III & 1.268 & 0.202 & 14.570 & 0.645 & 0.686 & 1 \\
\hline & Suspension IV & 0.249 & 0.015 & 0.513 & 0.539 & 0.001 & 1 \\
\hline \multirow[t]{2}{*}{$t_{60}\left(25^{\circ} \mathrm{C}\right)$} & Suspension III & 0.752 & 0.103 & 96.66 & 0.565 & 0.079 & 1 \\
\hline & Suspension IV & 0.181 & 0.015 & 0.777 & 0.538 & 0.005 & 1 \\
\hline \multirow[t]{2}{*}{$t_{60}\left(40^{\circ} \mathrm{C}\right)$} & Suspension III & 0.727 & 0.180 & 51.340 & 0.703 & 0.034 & 1 \\
\hline & Suspension IV & 0.106 & 0.014 & 2.717 & 0.691 & 0.002 & 1 \\
\hline
\end{tabular}

Table 4. Particle Size Distribution of the Suspensions at $t_{0}$ and $t_{60}$

\begin{tabular}{|c|c|c|c|c|c|c|}
\hline \multicolumn{7}{|c|}{ Particle size $(\mu \mathrm{m})$} \\
\hline & \multicolumn{3}{|c|}{$t_{0}$} & \multicolumn{3}{|c|}{$t_{60}$} \\
\hline & d10\% & d50\% & d90\% & d10\% & d50\% & d $90 \%$ \\
\hline Spl & $16.2 \pm 0.2$ & $35.4 \pm 0.8$ & $73.7 \pm 0.5$ & $15.4 \pm 0.5$ & $28.4 \pm 0.7$ & $73.1 \pm 0.9$ \\
\hline Spll & $6.6 \pm 0.5$ & $14.1 \pm 0.8$ & $27.9 \pm 0.9$ & $8.2 \pm 0.8$ & $16.3 \pm 0.9$ & $30.4 \pm 0.8$ \\
\hline Splll & $5.5 \pm 0.2$ & $12.7 \pm 0.2$ & $26.9 \pm 0.6$ & $9.1 \pm 0.6$ & $17.8 \pm 0.9$ & $33.1 \pm 0.4$ \\
\hline SpIV & $8.8 \pm 0.8$ & $18.2 \pm 0.9$ & $33.3 \pm 0.7$ & $10.7 \pm 0.4$ & $21.3 \pm 0.7$ & $41.9 \pm 0.9$ \\
\hline
\end{tabular}

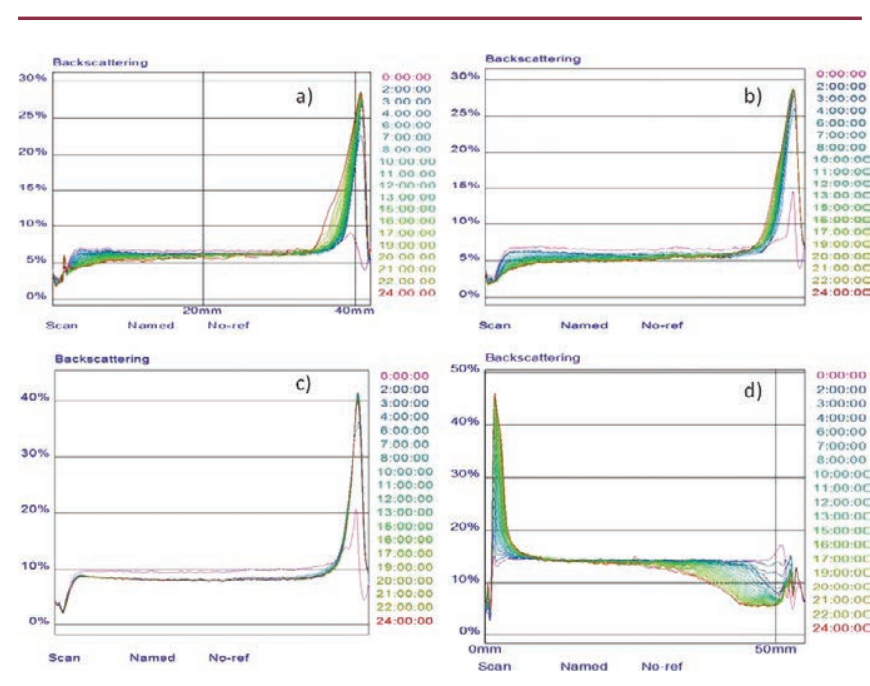

Figure 2. Backscattering profiles for suspensions (a) Spl, (b) Spll, (c) SpIII, and (d) SpIV.

formation. The presence of solvents and cosolvents (sorbitol, glycerin, PEG-40) in SpIV, together with suspending agents like carrageenan, which is a hydrophilic colloid that coats hydrophobic particles, and flocculating agents (calcium sulfate, sodium phosphate), helped the sedimentation of spironolactone, as shown in Figure 2. The presence of these ingredients in SpIV could also explain the second PSD obtained at day 60 . Something different occurred for
Spl, Spll, and SpIII, in which the backscattering level decreased at the bottom (clarification) and increased at the top. This behavior could indicate that the chosen wetting agent, glycerin, was not enough to wet the particles of spironolactone, and thus flotation was observed. Destabilization was slower for SpIV than for the other suspensions. This characteristic is desirable, as it allows the formulation to remain homogenous longer. All the formulations were resuspendable, despite the occurrence of flotation or sedimentation. However, to achieve good redispersion of the particles and thus a homogeneous and correct dosage, sedimentation is more desirable than flotation.

\section{Chemical Stability}

The $\mathrm{pH}$ of SpIV was around 4.5, which is the optimum $\mathrm{pH}$ of spironolactone as reported in the literature (44). Spl, Spll, and Splll had pH values of around 6.5, probably due to the presence of potassium sorbate from the simple syrup (1), which does not contain any other acidic substances. In all cases, the measured $\mathrm{pH}$ remained fairly constant after two months of study (Table 5). As reported by other authors (1), the $\mathrm{pH}$ was not affected by temperature in any of the formulations. The above-optimum $\mathrm{pH}$ for spironolactone that was observed in Spl, Spll, and SpIII did not affect the amount of active ingredient present in the different formulations.

No peaks attributable to canrenone were detected after a preliminary comparative study carried out at 242 
and $280 \mathrm{~nm}$. Thus, spironolactone was assayed during the stability study under the specified conditions at 242 $\mathrm{nm}$ (the maximum wavelength of absorbance for spironolactone). The HPLC method for the quantification of spironolactone in the suspensions was linear, precise, and accurate in the concentration range of $25-0.78 \mu \mathrm{g} /$ $\mathrm{mL}$. LOD and LOQ are $0.22 \pm 0.26 \mu \mathrm{g} / \mathrm{mL}$ and $0.68 \pm 0.79$ $\mu \mathrm{g} / \mathrm{mL}$, respectively, which confirm the sensitivity of the method. The accuracy values reported in Table 6 are within acceptable limits $(<10 \%)$. The small percentage differences between the nominal and found concentrations of the standards show that the assay is accurate enough for its application. The between-day precision results are also depicted in Table 6, and the RSD values are less than $10 \%$ at all concentrations. These data clearly indicate that the assay method is reproducible between days.

The method was selective under the aforementioned chromatographic conditions, as the excipient peaks did not interfere with the spironolactone peak, which did not change and remained the same retention time (about $12.0 \mathrm{~min}$ ) throughout the study (Figure 3 ).
Regarding the uniformity of the suspensions, the mean recovery (\%) for all of them was within the acceptable interval $\pm 10 \%$ of the labeled amount, as shown in Table 7 . SpIll showed the lowest percent recovery and the highest RSD (\%), probably due to its higher viscosity that allows the particles to remain in suspension longer, but also makes redispersion more difficult.

The analytical results show that the spironolactone content of all suspensions remained above $90 \%(\mathrm{w} / \mathrm{v})$ of the original amount throughout the 60-day study, regardless of temperature. There were no statistically significant differences in the content of spironolactone for Spl, Spll, and SpIV between $t_{0}$ and $t_{60}$. However, as shown in Figure 4 and in line with the mean recovery (\%) results, Splll registered statistically significant variability $(p<0.05)$ in spironolactone content at 4 and $25^{\circ} \mathrm{C}$. This variability was probably due to the higher viscosity at these temperatures, which could hinder sampling and the homogeneous distribution of spironolactone in the suspension. Higher temperatures decreased the viscosity of the formula, which facilitated sampling and homogeneity, and thus at $40^{\circ} \mathrm{C}$ the results were more constant. Therefore,

Table 5. Suspension pH Values (Median) at Different Times and Temperatures

\begin{tabular}{|c|c|c|c|c|c|c|}
\hline \multirow{2}{*}{ Formulation } & \multirow{2}{*}{ Temperature $\left({ }^{\circ} \mathrm{C}\right)$} & \multicolumn{5}{|c|}{ Time (Days) } \\
\hline & & 0 & 7 & 15 & 30 & 60 \\
\hline \multirow[t]{3}{*}{ Suspension I } & 4 & - & $6.9 \pm 0.03$ & $6.6 \pm 0.03$ & $6.5 \pm 0.70$ & $6.3 \pm 0.20$ \\
\hline & 25 & $6.5 \pm 0.03$ & $7.0 \pm 0.04$ & $6.6 \pm 0.02$ & $6.2 \pm 0.30$ & $6.0 \pm 0.30$ \\
\hline & 40 & - & $6.7 \pm 0.02$ & $6.5 \pm 0.01$ & $6.1 \pm 0.40$ & $6.0 \pm 0.30$ \\
\hline \multirow[t]{3}{*}{ Suspension II } & 4 & & $6.9 \pm 0.02$ & $6.9 \pm 0.03$ & $6.7 \pm 0.20$ & $6.1 \pm 0.10$ \\
\hline & 25 & $6.6 \pm 0.1$ & $6.9 \pm 0.02$ & $6.8 \pm 0.02$ & $6.8 \pm 0.20$ & $6.2 \pm 0.20$ \\
\hline & 40 & & $6.7 \pm 0.03$ & $6.7 \pm 0.01$ & $6.5 \pm 0.10$ & $6.4 \pm 0.20$ \\
\hline \multirow[t]{3}{*}{ Suspension III } & 4 & & $6.5 \pm 0.02$ & $6.5 \pm 0.03$ & $6.5 \pm 0.03$ & $6.0 \pm 0.10$ \\
\hline & 25 & $6.4 \pm 0.30$ & $6.6 \pm 0.06$ & $6.5 \pm 0.03$ & $6.5 \pm 0.01$ & $6.0 \pm 0.10$ \\
\hline & 40 & & $6.6 \pm 0.03$ & $6.4 \pm 0.07$ & $6.2 \pm 0.01$ & $6.1 \pm 0.07$ \\
\hline \multirow[t]{3}{*}{ Suspension IV } & 4 & - & $4.3 \pm 0.08$ & $4.2 \pm 0.03$ & $4.2 \pm 0.06$ & $4.1 \pm 0.01$ \\
\hline & 25 & $4.2 \pm 0.01$ & $4.2 \pm 0.01$ & $4.1 \pm 0.01$ & $4.2 \pm 0.01$ & $4.1 \pm 0.01$ \\
\hline & 40 & - & $4.2 \pm 0.02$ & $4.2 \pm 0.05$ & $4.2 \pm 0.02$ & $4.2 \pm 0.01$ \\
\hline
\end{tabular}

Table 6. Accuracy and Precision Parameters for Spironolactone Quantification

\begin{tabular}{ccccc}
\hline Concentration $(\boldsymbol{\mu} \mathbf{g} / \mathbf{m L})$ & Average & Standard Deviation & Relative Error (\%) & Relative Standard Deviation (\%) \\
\hline 50 & 50.01 & 0.104 & -0.035 & 0.208 \\
\hline 25 & 25.00 & 0.223 & -0.001 & 0.894 \\
\hline 12.5 & 12.40 & 0.385 & 0.777 & 3.101 \\
\hline 6.25 & 6.28 & 0.098 & -0.490 & 1.429 \\
\hline 3.125 & 3.16 & 0.077 & -1.083 & 2.193 \\
\hline 1.56 & 1.57 & 0.045 & -0.947 & 2.882 \\
\hline 0.78 & 0.79 & 0.074 & -0.824 & 9.454 \\
\hline
\end{tabular}


Table 7. Recovery (\%) of the Suspensions

\begin{tabular}{lcccc}
\hline \multicolumn{1}{c}{ Formulation } & Drug content $(\mathbf{m g})$ & Found $(\mathbf{m g})$ & \% Mean Recovery $(\boldsymbol{n}=\mathbf{6})$ & Relative Standard Deviation $(\%)$ \\
\hline Suspension I & 500 & 499.36 & 99.87 & 3.06 \\
\hline Suspension II & 500 & 502.27 & 100.45 & 4.73 \\
\hline Suspension III & 500 & 485.58 & 97.11 & 9.28 \\
\hline Suspension IV & 500 & 496.92 & 99.38 & 1.34 \\
\hline
\end{tabular}

based on the results, spironolactone was stable in all the studied formulations for 60 days at 4,25 , and $40^{\circ} \mathrm{C}$.

\section{Dissolution Test}

Dissolution studies have great significance because, in most cases, drug dissolution is the rate-limiting step in the absorption process. As occurs with solid oral dosage forms, heterogeneous disperse systems (suspensions) could also have some problems with in vitro dissolution (45).

The dissolution test of the suspensions was performed and the results were compared with the dissolution profiles of the commercially available tablets $(25 \mathrm{mg}$ of spironolactone).

In vitro dissolution has been recognized as an important element in drug development, and under certain conditions, it can be used as a potential surrogate marker of bioequivalence $(46,47)$.

This comparative study has not yet been reported in the literature, but it is very important, as the composition of the suspensions could modify the dissolution time and affect the velocity of absorption of the active substance. The UV spectrophotometric method used to quantify spironolactone in the dissolution test was linear,

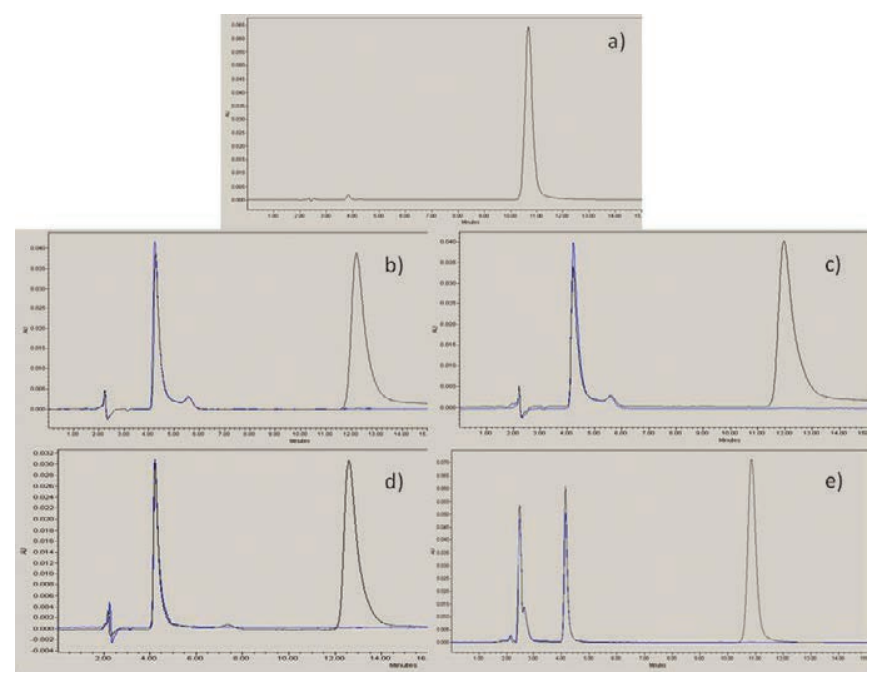

Figure 3. Chromatographic profiles of the (a) spironolactone standard; superposed chromatograms of blank (blue line) and sample (black line) for suspensions (b) Spl, (c) Spll, (d) Splll, and (e) SpIV. accurate, and precise over a range of concentrations from 1.56 to $25 \mu \mathrm{g} / \mathrm{mL}$. The LOD and LOQ were $0.19 \pm 0.16 \mu \mathrm{g} /$ $\mathrm{mL}$ and $0.60 \pm 0.50 \mu \mathrm{g} / \mathrm{mL}$, respectively. Accuracy values (\%RE) were less than $6.06 \%$ and thus within acceptable limits $(<10 \%)$. The small percentage difference between the nominal and found concentration of the standards show that the assay is accurate enough for its application. Results for between-day precision (\%RSD), ranging from 0.30 to $6.30 \%$, clearly indicate that the assay method was reproducible between days.

The in vitro drug release test revealed that Spl, Spll, and SpIV dissolved almost immediately. However, this was not the case for Splll, which took around 10 min to achieve the maximum concentration of active substance. The delay in the release of spironolactone in Splll could be due to the presence of $\mathrm{CMC}$ together with simple syrup. Thus, the presence of these excipients could lead in variations in the velocity of spironolactone absorption.

The dissolution profiles of Splll and the marketed tablets were compared. Parameters that were independent of the release model, such as $D E$ and $M D T$, were calculated with the experimental values $(n=6)$ for both formulations. The results are shown in Table 8. As expected, MDT was higher and $D E$ was lower for the tablets than for the suspension.

A criterion for selecting the most appropriate drug release model was based on the best fitting model, which had the lowest value of $A I C$ and the highest correlation
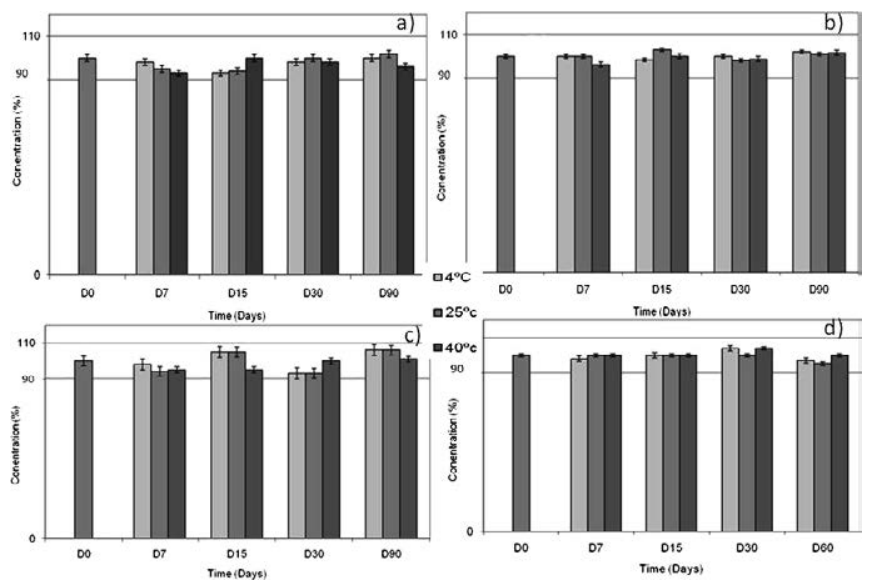

Figure 4. Stability of spironolactone in the suspensions over 60 days for suspensions (a) Spl, (b) Spll, (c) SpllI, and (d) SpIV. 
coefficient of the linear regression $\left(r^{2}\right)$ and thus statistically described the best drug release mechanism. For Splll, the model that best fit the data was the Boltzmann sigmoid. In general, the Boltzmann model is used to simulate the transport and reaction of fluids in porous media (48). In this case, the polymer (CMC) probably performs a function similar to porous matrices and, therefore, presents the same model. Other authors (49) used a coupled multiphase lattice Boltzmann model to simulate the dissolution of immiscible liquid droplets in another liquid during the rising process resulting from buoyancy. However, for the tablets, a two-phase exponential association model fit the data best. This model is used when the measured outcome is the result of the sum of a fast and slow exponential decay. In our case, this could be due to the quick dissolution of the film coat of the tablets at the beginning and a subsequent slow disintegration due to the excipients (calcium sulfate or cornstarch) that limits the dissolution process.

Best-fit and goodness-of-fit values for both models are reported in Table 9. The mean dissolution profiles $(n=6)$ for Splll and for the tablet are shown in Figure 5.

\section{Microbiological Stability}

Microbial contamination in nonsterile liquid formulations may cause a foul odor, turbidity, and adversely affect palatability and appearance. Otherwise, a high level of microorganisms may be hazardous to health, especially in immunocompromised patients.

\section{Table 8. Dissolution Parameters Independent of the Model}

\begin{tabular}{cccc}
\hline Formulation & MDT $(\mathbf{m i n})$ & AUC (mg min) & DE (\%) \\
\hline Tablet & 10.2 & 1317.8 & 82.9 \\
\hline Suspension III & 4.8 & 1403.0 & 91.8 \\
\hline $\begin{array}{l}\text { AUC: } \text { area under the curve; MDT: mean dissolution profile; DE: Dissolution } \\
\text { Efficiency. }\end{array}$
\end{tabular}
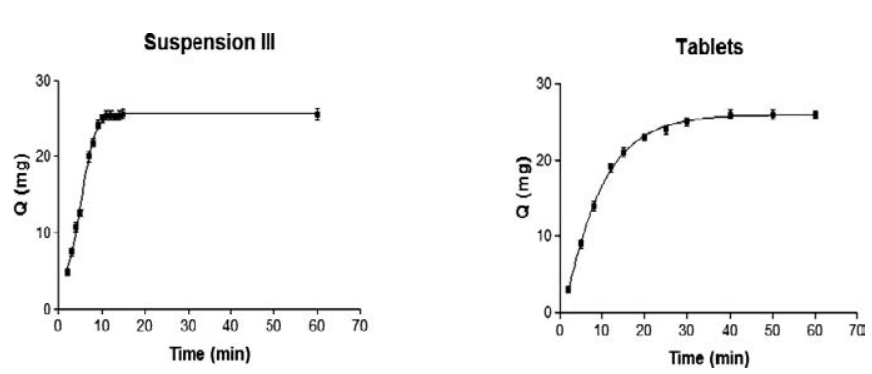

Figure 5. Dissolution profiles of SpIll and the marketed tablets.

Taking into account all the studied parameters, the microbiological test of SpIV was performed. No E. Coli contamination was observed, the total bacteria count was below $10^{2} \mathrm{cfu} / \mathrm{g}$, and the fungal contamination was below $10^{1} \mathrm{cfu} / \mathrm{g}$ at day 60 of the study. These results indicate that SpIV complied with the European Pharmacopoeia specifications on the microbial examination of non-sterile product at 60 days.

\section{CONCLUSIONS}

Four alcohol-free extemporaneous suspensions containing $5 \mathrm{mg} / \mathrm{mL}$ of spironolactone were prepared from drug powder. In general, the spironolactone extemporaneous formulation was kept as simple as possible, using simple syrup as the only selected vehicle. However, this suspension had the largest particle size, and flotation occurred. Glycerin, used as a wetting agent, was not enough to wet the particles in Spll and SpllI. The results suggest that Splll was the least suitable due to its high viscosity, which made it difficult to achieve homogeneous redispersion. An accurate dosage is always very important, especially in the pediatric population. Furthermore, drug release in SpIII was slower than in the other formulations, which indicates that the presence of some excipients could have an influence on the dissolution profile of the suspensions. Only

Table 9. Best-Fit Values and Goodness of Fit for Boltzman Sigmoid (Suspension) and Two-Phase Exponential Association (Tablets)

\begin{tabular}{|c|c|c|c|}
\hline \multicolumn{2}{|c|}{ Best-Fit Values for Suspension III } & \multicolumn{2}{|c|}{ Goodness of Fit (Boltzman sigmoid) } \\
\hline Bottom & $2.33 \mathrm{mg}$ & Degrees of Freedom & 10 \\
\hline Top & $25.61 \mathrm{mg}$ & $\mathrm{R}^{2}$ & 0.9967 \\
\hline V50 & $5.16 \mathrm{~min}$ & Absolute sum of squares & 2.481 \\
\hline Slope & $1.61 \mathrm{~min}$ & Sy.x & 0.4981 \\
\hline \multicolumn{2}{|c|}{ Best-Fit Values for Tablets } & \multicolumn{2}{|c|}{ Goodness of Fit (Two-phase exponential) } \\
\hline YMAX1 & $-5.20 \mathrm{mg}$ & Degrees of Freedom & 7 \\
\hline K1 & $0.62 \min ^{-1}$ & $\mathrm{R}^{2}$ & 0.9999 \\
\hline YMAX2 & $31.18 \mathrm{mg}$ & Absolute sum of squares & 0.08646 \\
\hline $\mathrm{K} 2$ & $0.12 \mathrm{~min}^{-1}$ & Sy.x & 0.1111 \\
\hline Halflife_1 & $1.10 \mathrm{~min}$ & & \\
\hline Halflife_2 & $5.76 \mathrm{~min}$ & & \\
\hline
\end{tabular}


SpIV had an optimum $\mathrm{pH}$ and the best physical stability. SpIV was also microbiologically stable for at least 60 days.

\section{ACKNOWLEDGMENTS}

The authors would like to thank Dr. L. Halbaut for technical support in the rheological studies, Dr. Gonzalez for her technical support in interpreting optical stability spectra, Language Services from the University of Barcelona for the correction of the paper, and the Permanent Commission for Uniform Compounding Pediatric Criteria for their help.

\section{REFERENCES}

1. Salgado, A. C.; Rosa, M. L.; Duarte, M. A.; Almeida, A. J. Stability of spironolactone in an extemporaneously prepared aqueous suspension: the importance of microbiological quality of compounded paediatric formulations. Eur. J. Hosp. Pharm. Sci. 2005, 11 (3), 68-73.

2. Walker, R. D.; Cumming, G. R. Response of the Infant Kidney to Diuretic Drugs. Can. Med. Assoc. J. 1964, 91 (22), 1149-1153.

3. Noerr, B. Spironolactone. Neonatal Netw. 1999, 18 (3), 43-46. DOI: 10.1891/0730-0832.18.3.43.

4. Hobbins, S. M.; Fowler, R. S.; Rowe, R. D.; Korey, A. G. Spironolactone Therapy in Infants with Congestive Heart Failure Secondary to Congenital Heart Disease. Arch. Dis. Child. 1981, 56, 934-938. DOI: 10.1136/ adc.56.12.934.

5. Buck, M. L. Clinical Experience with Spironolactone in Pediatrics. Ann. Pharmacother. 2005, 39 (5), 823-828. DOI: 10.1345/aph.1E618.

6. Kao, L. C.; Warburton, D.; Cheng, M. H.; Cedeño, C.; Platzker, A. C.; Keens, T. G. Effect of oral diuretics on pulmonary mechanics in infants with chronic bronchopulmonary dysplasia: results of a double-blind crossover sequential trial. Pediatrics 1984, 74, 37-44.

7. Albersheim, S. G.; Solimano, A. J.; Sharma, A. K.; Smyth, J. A.; Rotschild, A.; Wood, B. J.; Sheps, S. B. Randomized, double-blind, controlled trial of longterm diuretic therapy for bronchopulmonary dysplasia. J. Pediatr. 1989, 115 (4), 615-620. DOI: 10.1016/S00223476(89)80297-5.

8. Danks, D. M. Diuretic Therapy in Infants and Children. J. Pediatr. 1976, 88 (4), 695-696. DOI: 10.1016/S00223476(76)80047-9.

9. Sabri, M.; Saps, M.; Peters, J. M. Pathophysiology and management of pediatric ascites. Curr. Gastroenterol. Rep. 2003, 5 (3), 240-246. DOI: 10.1007/s11894-0030026-6.

10. Glass, B. D.; Haywood, A. Stability considerations in liquid dosage forms extemporaneously prepared from commercially available products. J. Pharm. Pharm. Sci. 2006, 9 (3), 398-426.

11. Saavedra, I.; Quiñones, L.; Saavedra, M.; Sasso, J.; León, J.; Roco, A. Farmacocinética de medicamentos de uso pediátrico, visión actual. Rev. Chil. Pediatr. 2008, 79 (3), 249-258. DOI: 10.4067/S0370-41062008000300002.

12. Standing, J. F.; Tuleu, C. Paediatric formulationsGetting to the heart of the problem. Int. J. Pharm. 2005, 300 (1-2), 56-66. DOI: 10.1016/j.jpharm.2005.05.006.

13. Costello, l.; Long, P. F; Wong, I. C. K.; Tuleu, C.; Yeung, V. Paediatric Drug Handling; Pharmaceutical Press: London, 2007.

14. Thomson, S. A.; Tuleu, C.; Wong, I. C. K.; Keady, S.; Pitt, K. G.; Sutcliffe A. G. Minitablets: New Modality to Deliver Medicines to Preschool-Aged Children. Pediatrics 2009, 123 (2), e235-e238. DOl: 10.1542/ peds.2008-2059.

15. Viriyaroj, A.; Klapachan, S.; Phanpleewan, C.; Viriyaroj, V.; Sornchainthawatwong, C.; Wiranidchapong, C. Physicochemical and Microbiological stability of Phenytoin Sodium Extemporaneous Suspension. Thai. Pharm. Health Sci. J. 2009, 4 (4), 463-470.

16. Allen, L. V. Dosage form design and development. Clin. Ther. 2008, 30 (11), 2102-2111. DOI: 10.1016/j. clinthera.2008.11.015.

17. James, A. The legal and clinical implications of crushing tablet medication. Nurs. Times 2005, 100 (50), 28-29.

18. Brion, F.; Nunn, A. J.; Rieutord, A. Extemporaneous (magistral) preparation of oral medicines for children in European hospitals. Acta Paediatr. 2003, 92, 486-490. DOI: 10.1111/j.1651-2227.2003.tb00583.x.

19. Santoveña, A.; Hernández-Paiz, Z.; Fariña, J. B. Design of a pediatric oral formulation with a low proportion of hydrochlorothiazide. Int. J. Pharm. 2012, 423 (2), 360-364. DOI: 10.1016/j.ijpharm.2011.11.034.

20. Das Gupta, V.; Gibbs, C. W.; Ghanekar, A. G. Stability of pediatric liquid dosage forms of ethacrynic acid, indomethacin, methyldopate hydrochloride, prednisone and spironolactone. Am. J. Hosp. Pharm. 1978, 35 (11), 1382-1385.

21. Mathur, L. K.; Wickman, A. Stability of extemporaneously compounded spironolactone suspensions. Am. J. Hosp. Pharm. 1989, 46 (10), 2040-2042.

22. Pramar, Y.; Das Gupta, V.; Bethea C. Development of a stable oral liquid dosage form of spironolactone. $J$. Clin. Pharm. Ther. 1992, 17 (4), 245-248. DOI: 10.1111/ j.1365-2710.1992.tb01300.x.

23. Nahata, M. C.; Morosco, R. S.; Hipple, T. F. Stability of spironolactone in an extemporaneously prepared suspension at two temperatures. Ann. Pharmacother. 1993, 27 (10), 1198-1199.

24. Allen, L. V. Jr.; Ericson, M. A. 3rd. Stability of ketoconazole, metolazone, metronidazole, procainamide hydrochloride, and spironolactone in extemporaneously compounded oral liquids. Am. J. Health-Syst. Pharm. 1996, 53 (17), 2073-2078.

25. Allen, L. V. Jr.; Ericson, M. A. 3rd. Stability of labetalol hydrochloride, metoprolol tartarate, verapamil hydrochloride, and spironolactone with hydrochlorotiazide 
in extemporaneously compounded oral liquids. Am. J. Health-Syst. Pharm. 1996, 53, 2304-2309.

26. Asiri, Y. A.; Bawazir, S. A.; Al-Hadiya, B. M.; Gubara, O. A.; Al-Khamis, K. I. Stability of extemporaneously prepared spironolactone suspensions in Saudí hospitals. Saudi Pharm. J. 2001, 9 (2), 106-112.

27. Celia, C.; Trapasso, E.; Cosco, D.; Paolino, D.; Fresta, M. Turbiscan Lab ${ }^{\oplus}$ Expert analysis of the stability of ethosomes ${ }^{\oplus}$ and ultradeformable liposomes containing a bilayer fluidizing agent. Colloids Surf., B 2009, 72 (1), 155-160. DOI: 10.1016/j.colsurfb.2009.03.007.

28. Lemarchand, C.; Couvreur, P.; Vauthier, C.; Costantini, D.; Gref, R. Study of emulsion stabilization by graft copolymers using the optical analyzer Turbiscan. Int. J. Pharm. 2003, 254 (1), 77-82. DOI: 10.1016/S03785173(02)00687-7.

29. Gonzalez-Mira, E.; Egea, M. A.; Garcia, M. L.; Souto, E. B. Design and ocular tolerance of flurbiprofen loaded ultrasound-engineered NLC. Colloids Surf., B 2010, 81 (2), 412-421. DOI: 10.1016/j.colsurfb.2010.07.029.

30. European Pharmacopoeia, 7th ed.; European Directorate for the Quality of Medicines \& Healthcare, Council of Europe: Strasbourg, France, 2011.

31. International Conference on Harmonisation of Technical Requirements for Registration of Pharmaceuticals for Human Use. Validation of Analytical Procedures: Text and Methodology, Q2(R1); ICH Harmonised Tripartite Guideline: Geneva, Switzerland, 2005. http://www. ich.org/fileadmin/Public_Web_Site/ICH_Products/ Guidelines/Quality/Q2_R1/Step4/Q2_R1_Guideline.pdf (accessed Jan 8, 2014).

32. Araújo, J.; Garcia, M. L.; Mallandrich, M.; Souto, E. B.; Calpena, A. C. Release profile and transscleral permeation of triamcinolone acetonide loaded nanostructured lipid carriers (TA-NLC): in vitro and ex vivo studies. Nanomedicine 2012, 8 (6), 1034-1041. DOI: 10.1016/j.nano.2011.10.015.

33. The United States Pharmacopeia and National Formulary USP 32-NF 27; The United States Pharmacopeial Convention, Inc.: Rockville, MD, 2009.

34. Yamaoka, K.; Nakagawa, T.; Uno, T. Application of Akaike's information criterion (AIC) in the evaluation of linear pharmacokinetic equations. J. Pharmacokinet. Biopharm. 1978, 6 (2), 165-175. DOl: 10.1007/BF01117450.

35. Sierra Villar, A. M.; Clares Naveros, B.; Calpena Campmany, A. C.; Aróztegui Trenchs, M.; Barbé Rocabert, C.; Halbaut Bellowa, L. Design and optimization of self-nanoemulsifying drug delivery systems (SNEDDS) for enhanced dissolution of gemfibrozil. Int. J. Pharm. 2012, 431 (1-2), 161-175. DOI: 10.1016/j. ijpharm.2012.04.001.

36. Nahata, M. C.; Allen, L. V. Extemporaneous drug formulations. Clin. Ther. 2008, 30 (11), 2112-2119. DOI: 10.1016/j.clinthera.2008.11.020.
37. Ferry, A.-L.; Hort, J.; Mitchell, J. R.; Cook, D. J.; Lagarrigue, S.; Valles Pamies, B. Viscosity and flavour perception: Why is starch different from hydrocolloids? Food Hydrocolloids 2006, 20 (6), 855-862. DOI: 10.1016/j.foodhyd.2005.08.008.

38. Schellart, W. P. Rheology and density of glucose syrup and honey: Determining their suitability for usage in analogue and fluid dynamic models of geological processes. J. Struct. Geol. 2011, 33 (6), 1079-1088. DOI: 10.1016/j.jsg.2011.03.013.

39. Lee, C. H.; Moturi, V.; Lee, Y. Thixotropic property in pharmaceutical formulations. J. Controlled Release 2009, 136 (2), 88-98. DOI: 10.1016/j.jconrel.2009.02.013.

40. Cancela, M. A.; Álvarez, E.; Maceiras, R. Effects of temperature and concentration on carboxymethylcellulose with sucrose rheology. J. Food. Eng. 2005, 71 (4), 419424. DOI: 10.1016/j.jfoodeng.2004.10.043.

41. Benchabane, A.; Bekkour, K. Rheological properties of carboxymethyl cellulose (CMC) solutions. Colloid Polym. Sci. 2008, 286 (10), 1173-1180. DOI: 10.1007/ s00396-008-1882-2.

42. Oral Solutions and Suspensions (8/94); Guide to Inspections; U.S. Department of Health and Human Services, Food and Drug Administration, Center for Drug Evaluation and Research (CDER), U.S. Government Printing Office: Washington, DC, 2009.

43. Pharmaceutical Suspensions: From Formulation Development to Manufacturing; Kulshreshtha, A. K., Singh, O. N., Wall, G. M., Eds.; Springer: New York, 2010. DOI: 10.1007/978-1-4419-1087-5.

44. Pramar, Y.; Gupta, V. D. Preformulation studies of spironolactone: Effect of $\mathrm{pH}$, two buffer species, ionic strength, and temperature on stability. J. Pharm. Sci. 1991, 80 (6), 551-553. DOI: 10.1002/ jps.2600800611.

45. Gonzalez Vidal, N. L.; Zubata, P. D.; Simionato, L. D.; Pizzorno, M. T. Dissolution Stability Study of Cefadroxil Extemporaneous Suspensions. Dissolution Technol. 2008, 15 (3), 29-36.

46. Costa, P.; Sousa Lobo, J. M. Modeling and comparison of dissolution profiles. Eur. J. Pharm. Sci. 2001, 13 (2), 123-133. DOI: 10.1016/S0928-0987(01)00095-1.

47. Gowthamarajan, K.; Singh, S. K. Dissolution Testing for Poorly Soluble Drugs: A Continuing Perspective. Dissolution Technol. 2010, 17 (3), 24-32.

48. Kang, Q.; Zhang, D.; Chen, S.; He, X. Lattice Boltzmann simulation of chemical dissolution in porous media. Phys. Rev. E: Stat., Nonlinear, Soft Matter Phys. 2002, 65 (3). DOI: 10.1103/PhysRevE.65.036318.

49. Chen, C.; Zhang, D. Lattice Boltzmann simulation of the rise and dissolution of two-dimensional immiscible droplets. Phys. Fluids 2009, 21 (10), 103301. DOI: 10.1063/1.3253385.50. 